\title{
A hemizygous mutation in the FOXP3 gene (IPEX syndrome) resulting in recurrent X-linked fetal hydrops: a case report
}

\author{
Panicos Shangaris ${ }^{1 *+} \mathbb{D}$, Alison Ho ${ }^{1 \dagger}$, Andreas Marnerides 5 , Simi George ${ }^{5}$, Mudher AlAdnani ${ }^{5}$, Shu Yau ${ }^{2}$, \\ Mattias Jansson'2, Jacqueline Hoyle ${ }^{2}$, Joo Wook Ahn², Sian Ellard ${ }^{3}$, Melita Irving ${ }^{2}$, Diana Wellesley ${ }^{4}$, \\ Dharmintra Pasupathy ${ }^{1,6+}$ and Muriel Holder-Espinasse ${ }^{2+}$
}

\begin{abstract}
Background: Fetal hydrops is excessive extravasation of fluid into the third space in a fetus, which could be due to a wide differential of underlying pathology. IPEX (immune dysregulation, polyendocrinopathy, enteropathy, X-linked) syndrome primarily affects males. It is a monogenic primary immunodeficiency syndrome of X-linked recessive inheritance due to FOXP3 gene variants. It is characterised by the development of multiple autoimmune disorders in affected individuals.

Case presentation: We present a rare cause of male fetal hydrops in the context of IPEX syndrome and discuss FOXP3 gene variants as a differential for 'unexplained'fetal hydrops that may present after the first trimester.

Discussion and conclusions: In all similar cases, the pathological process begins during intrauterine life. Furthermore, there are no survivors described. Consequently, this variant should be considered as a severe one, associated with intrauterine life onset and fatal course, i.e., the most severe IPEX phenotype.
\end{abstract}

Keywords: IPEX syndrome, FOXP3, Fetal hydrops, In utero transfusion

\section{Background}

The immune dysregulation-polyendocrinopathy-enteropathy $\mathrm{x}$-linked (IPEX) syndrome is a primary immunodeficiency caused by variants in the FOXP3 gene [1,2]. FOXP3 is a key control gene, which encodes a transcription factor regulating the development and function of regulatory $\mathrm{T}$ Cells (Tregs) [3]. Tregs are responsible for maintaining tolerance to self-antigens by suppressing the activity of autoreactive $T$ cells that have escaped from the

${ }^{*}$ Correspondence: panicos.shangaris@kcl.ac.uk

${ }^{\dagger}$ Panicos Shangaris and Alison Ho: Joint first authors

†Dharmintra Pasupathy and Muriel Holder-Espinasse: Joint senior authors

1 Department of Women and Children's Health, School of Life Course

Sciences, Faculty of Life Sciences and Medicine, King's College London,

10th Floor North Wing, St Thomas' Hospital, Westminster Bridge Road,

London SE1 7EH, UK

Full list of author information is available at the end of the article thymus [4]. IPEX syndrome can present antenatally, in the early neonatal period or later in life. The syndrome usually presents with severe enteropathy, chronic dermatitis, diabetes type 1 , hypoparathyroidism and other immune-related issues [2]. Male patients typically die within the first two years of life if untreated. The only available, proven, treatment is allogeneic haematopoietic stem cell transplantation [1].

\section{Case presentation}

A 28 year old Caucasian female in her first pregnancy with a low-risk quadruple test, underwent an anomaly ultrasound at 20weeks' and 6 days of gestation, revealing significant fetal hydrops (Fig. 1c, d). She had an unremarkable past medical history, no family history of note and no recent viral illness. Talipes of the right foot was the only structural abnormality noted. Growth and liquor

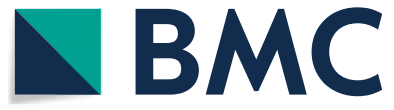

(c) The Author(s) 2021. Open Access This article is licensed under a Creative Commons Attribution 4.0 International License, which permits use, sharing, adaptation, distribution and reproduction in any medium or format, as long as you give appropriate credit to the original author(s) and the source, provide a link to the Creative Commons licence, and indicate if changes were made. The images or other third party material in this article are included in the article's Creative Commons licence, unless indicated otherwise in a credit line to the material. If material is not included in the article's Creative Commons licence and your intended use is not permitted by statutory regulation or exceeds the permitted use, you will need to obtain permission directly from the copyright holder. To view a copy of this licence, visit http://creativecommons.org/licenses/by/4.0/. The Creative Commons Public Domain Dedication waiver (http://creativeco mmons.org/publicdomain/zero/1.0/) applies to the data made available in this article, unless otherwise stated in a credit line to the data. 

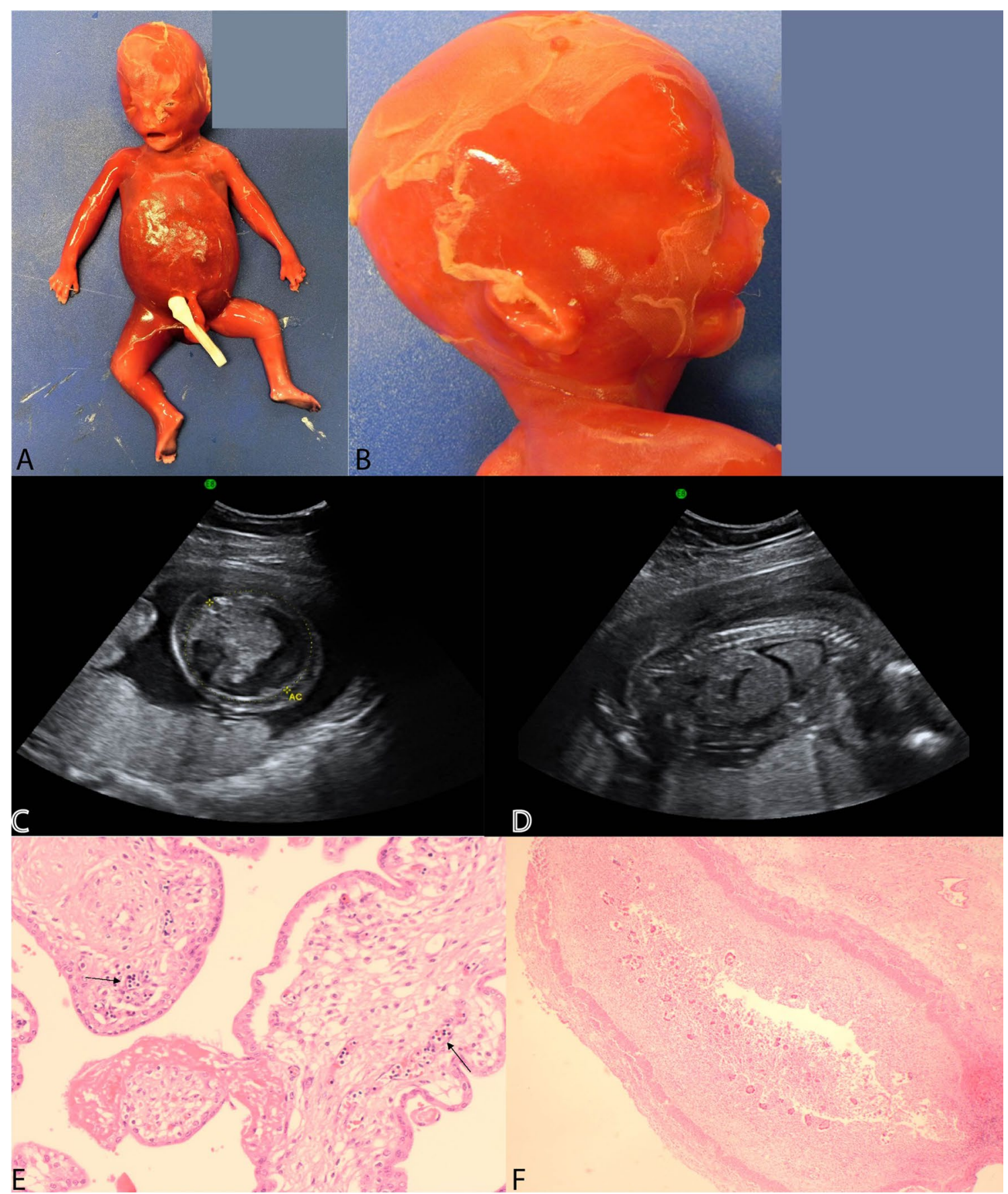

Fig. 1 IPEX Fetus legend. a Macerated hydropic male fetus. $\mathbf{b}$ Profile picture of a hydropic fetus with a low set, posteriorly rotated ears and micrognathia. c Transverse image of the abdomen showing severe ascites. d. Sagittal image of the affected fetus showing hydrops fetalis. e H\&E picture showing increased nucleated red cells in fetal vessels of chorionic villi (arrows). $\mathbf{f}$ H\&E picture showing autolysed intestines with no significant pathology

volume were normal; however, the MCA peak systolic velocity was above 1.5 Multiple of Median (MoM).

Fetal blood sampling was performed, which identified anaemia $(\mathrm{Hb} 60 \mathrm{~g} / \mathrm{L})$. In utero blood transfusion was performed $(15 \mathrm{ml})$; however, towards the end of the procedure, fetal demise occurred. Post-natal investigations were negative for red cell antibodies, thrombophilia screen and systemic lupus erythematosus. There 
was no evidence of fetal infection in the amniotic fluid. A hydropic male baby with intrauterine growth restriction (Fig. 1a), low-set ears, micrognathia (Fig. 1b), a rightsided talipes and malrotated intestines, was revealed at post mortem examination. The placenta's weight was above 90th centile with no evidence of abnormal trophoblast proliferation, mesenchymal dysplasia or storage disease. Oedematous villi, increased nucleated haematopoietic cells and decidual vasculopathy were identified (Fig. 1e). The pancreas, duodenum, small and large intestines were normally formed and focally autolysed on histology with no enteritis or intra-luminal inflammatory exudate (Fig. 1f).

Comparative genomic hybridisation (CGH) array analysis of DNA extracted from a rib using oligonucleotide arrays with $\sim 60,000$ probes across the genome was performed, and results were consistent with a normal male chromosome complement.

In her second pregnancy three years later, with a different partner, nuchal ultrasound was normal, and the first-trimester screening was 'low risk'. Booking blood tests were negative for antibody and haemoglobinopathy screening. Subsequent serial ultrasound scans at 12, 16 and 18 weeks' of gestation were normal; however, at 20 weeks' and 3 days of gestation, a recurrence of fetal hydrops was detected. No sonographic evidence of fetal anaemia was present, and both growth velocity and amniotic fluid index were normal. No structural abnormalities were identified. The patient was well with no history of recent illness. Subsequent repeat thrombophilia screen, complement $\mathrm{C} 3$, complement $\mathrm{C} 4$, anticardiolipin and lupus anticoagulant antibody were all normal, as was a fetal infection screen. Simpson-Golabi-Behmel syndrome was excluded through GPC3 gene molecular analysis on DNA extracted from the first fetus.

The patient declined invasive testing. She was managed expectantly with serial ultrasound scans and monitoring for maternal mirror syndrome. At 23 weeks' and 3 days of gestation, fetal movements were reduced, and contractures of both wrists and feet were identified. Acetylcholine receptor antibodies and IgG subsets were normal. At 25 weeks' and 3 days of gestation this progressed to bilateral talipes and persistent arm flexion. There was no evidence of fetal anaemia by MCA PSV doppler or abnormality of fetal echocardiography, but hydropic features had increased with hepatosplenomegaly. Given the rapid progression of fetal hydrops and poor prognosis, the couple opted for medical interruption of pregnancy.

A post mortem confirmed fetal hydrops with growth parameters in keeping with gestational age. The liver was enlarged, and two small accessory spleens were noted. The spleen, pancreas, large and small intestine showed extensive autolysis macroscopically and microscopically, not allowing any detailed histological assessment. These fetuses usually have CD3+ lymphocytic interstitial infiltration, CD4+ and CD8+ cells in the pancreatic parenchyma, as previously reported by Da Silva et al. [5].

There were no other abnormalities and no features suggestive of fetal anaemia. Virology of ascitic fluid, brain, heart, lung, liver and spleen tissue were negative. Antibody screen was negative. Array CGH showed a normal male chromosome complement.

Recurrence of fetal hydrops in two male pregnancies with different partners raised the suspicion of an $\mathrm{X}$-linked condition. Linkage analysis showed that both babies had inherited the same maternal X chromosome. Whole exome sequencing was performed using Agilent SureSelectXT Clinical Research Exome library on an Illumina HiSeq 2500. The data was processed using an inhouse pipeline with subsequent filtering and assessment of variants in QIAGEN Ingenuity Variant Analysis and identified a pathogenic heterozygous missense variant in exon 12 of the FOXP3 gene [NM_014009.3:c.1189C > T p.(Arg397Trp)] on the maternal DNA. Sanger sequencing confirmed this result. Both fetuses were tested and found to be hemizygous for this variant, confirming a diagnosis of IPEX syndrome. The patient subsequently, had a successful pregnancy. She had prenatal testing with CVS, which showed a male fetus not affected by the condition.

\section{Discussion and conclusions}

In the context of male fetal hydrops, variants in the FOXP3 gene and resultant IPEX syndrome may be a cause for 'unexplained' cases following routine investigations. Other known in utero presentations include severe intrauterine growth restriction, fetal akinesia and recurrent male miscarriages [5-7]. Fetal hydrops may appear after the first trimester [6-9]. Early onset autoimmune haemolytic anemia is probably the cause of fetal hydrops in IPEX, so we could argue that IPEX-associated hydrops should be considered an immune process $[10,11]$.

This report reinforces that IPEX should be considered as an underlying disease in recurrent male miscarriages as well as in unexplained fetal hydrops. In addition, this is the 6th report on fetal-onset IPEX over a two-year interval, which suggests that this defect is more frequent than previously estimated. Until 2015 only post-natal onset cases were recognised. In addition to previous reports [5-8], there is a recently published paper with two additional cases of fetal-onset IPEX [9].

The variant described in this case report was previously identified by Xavier-da-Silva et al. [5] in a Brazilian family in a fetus presenting with hydrops at 27 weeks' gestation and in a term newborn who developed diabetes mellitus during the first hours of life. The only other family with the same variant was reported by 
Levy-Lahad \& Wildin [12], who described three siblings from the USA, presenting with IPEX manifestations at birth. One of them was a preterm infant. All three individuals with the FOXP3 gene variant [c.1189C $>\mathrm{T}$, p.(Arg397Trp)] in exon 12, had IPEX manifestations during the fetal period or on the 1st day of life. Thus, in all cases, the pathological process begins during intrauterine life. Furthermore, there are no survivors described. Consequently, this variant should be considered as a severe one, associated with intrauterine life onset and fatal course, i.e., the most severe IPEX phenotype.

This is in contrast to other causes of fetal hydrops (such as chromosomal abnormality [13]) and may be due to compromised ability to develop self-tolerance, as the fetus is significantly challenged by its endogenous immune system in the second trimester. Post mortems have revealed lethal in utero reactive $\mathrm{T}$ cell infiltration of multiple organs, plurivisceral inflammation and the presence of Charcot-Leyden crystals [7].

IPEX syndrome is a rare monogenic primary immunodeficiency syndrome of X-linked recessive inheritance [4]. The incidence and carrier status of IPEX syndrome is unknown. IPEX syndrome (OMIM 304790) is due to variants in the FOXP3 gene mapped at Xp11.23, encoding a 431 amino acid transcriptional regulator protein forkhead box p3. FOXP3 is required to establish and maintain tolerance to self-antigens through the development and maintenance of $\mathrm{CD} 4+, \mathrm{CD} 25+$, Foxp3+ regulatory T cells [6].

Carrier females of IPEX syndrome are healthy, however, affected males typically present with neonatal-onset autoimmune endocrinopathies, enteropathies and dermatitis. Autoimmune phenomena include type 1 diabetes mellitus, pancytopenia, thyroid and renal disease. Immunodeficiency increases susceptibility to fatal infections. This constellation of pathologies leads to a poor prognosis and lethality, often as a neonate or within the first three years of life [6]. Current therapy for IPEX syndrome is supportive [14]. Immunosuppressive agents often fail due to toxicity and susceptibility to fatal infections. Haematopoietic stem cell transplant presents a potential management strategy [15]. The murine, equivalent to IPEX syndrome, is called a scurfy mouse. These mice are deficient in regulatory $\mathrm{T}$ cells. Manipulation of the scurfin protein, which is encoded by the FOXP3 gene, might prevent or treat IPEX $[16,17]$.

IPEX syndrome patients are usually uneventful antenatally and appear phenotypically normal at birth; however, cases of fetal presentation are emerging. Intrauterine disease onset has been described in four families, presenting in the form of severe intrauterine growth restriction, fetal akinesia [6] with progressive fetal hydrops $[5,7,8]$ and recurrent male miscarriages [5-7] before the second trimester.

Heightened awareness of IPEX syndrome as a differential for fetal hydrops is crucial for counselling of future pregnancies with a $50 \%$ risk of any subsequent male fetus being affected if the mother is a carrier. Carriers of IPEX syndrome are asymptomatic; thus, cascade screening is relevant to the patient's relatives. They should be offered testing in the contest of non-invasive or invasive prenatal testing as well as preimplantation genetic diagnosis and subsequent IVF.

\section{Abbreviations}

IPEX: Immune dysregulation, polyendocrinopathy, enteropathy, X-linked; FOXP3: Forkhead box P3; Tregs: Regulatory T Cells; Hb: Haemoglobin; CGH: Comparative genomic hybridisation; DNA: Deoxyribonucleic acid; MCA PSV: Middle cerebral artery peak systolic velocity; IVF: In vitro fertilisation.

\section{Acknowledgements}

We would like to thank rest of the team at Guy's and St Thomas' NHS Trust who cared for this patient.

The abstract has been published in the special issue of BJOG, Volume 124, Issue S2: Abstracts of the British Maternal and Fetal Medicine Society 19th Annual Conference 2017, 30-31 March 2017, Amsterdam, The Netherlands.

\section{Authors' contributions}

Designed Research Study: A.H., P.S. Acquired Data: A.M., S.G., M.A.A., S.Y., M.J, J.H., J.W.A., M.I., D.W. Interpret Data: A.M., S.G., M.A.A., S.Y., M.J., J.H., J.W.A., M.I., D.W. Analysed Data: P.S., A.H., D.P., M.H.E. Provided Expert Opinion: D.P., M.H.E., A.M., S.G. Writing the manuscript: P.S., A.H. Revising the Manuscript: D.P., M.H.E. Agreed both to be personally accountable for the author's own contributions and to ensure that questions related to the accuracy or integrity of any part of the work, even ones in which the author was not personally involved, are appropriately investigated, resolved, and the resolution documented in the literature: P.S., A.H., A.M., S.G., M.A.A., S.Y., M.J, J.H., J.W.A., S.E., M.I., D.W., D.P., M.H.E. All authors have read and approved the manuscript.

\section{Funding}

The research time which allowed P.S. to collect and analyzed data was funded by an NIHR Clinical Lectureship (CL-2018-17-002) and an Academy of Medical Sciences Starter Grant for Clinical Lecturers (SGL023\1023).

\section{Availability of data and materials}

The details of the variant analysed during the current study are available in the ClinVar repository, under the accession number SCV001468505. The raw datasets generated during the current study are not publicly available because it is possible that individual privacy could be compromised. It is possible to apply for permission to obtain access to the raw sequencing data and the details of the postmortem examination through the corresponding author.

Ethics approval and consent to participate

Written informed consent to participate was obtained from the patient.

\section{Consent for publication}

Written informed consent was obtained from the patient for publication of this case report and accompanying images.

\section{Competing interests}

The authors have no conflicts of interest to declare.

\section{Author details}

${ }^{1}$ Department of Women and Children's Health, School of Life Course Sciences, Faculty of Life Sciences and Medicine, King's College London, 10th Floor North Wing, St Thomas' Hospital, Westminster Bridge Road, London SE1 7EH, UK. ${ }^{2}$ Department of Clinical Genetics, Guy's and St Thomas' NHS Foundation Trust, London, UK. ${ }^{3}$ Department of Molecular Genetics, Royal Devon \& Exeter 
Hospital, Barrack Road, Exeter EX2 5DW, UK. ${ }^{4}$ Wessex Clinical Genetics Service, Princess Anne Hospital, Southampton SO16 5YA, UK. ${ }^{5}$ Department of Histopathology, St Thomas Hospital, Westminster Bridge Road, London SE17EH, UK. ${ }^{6}$ Discipline of Obstetrics, Gynaecology and Neonatology, Westmead Clinical School, Faculty of Medicine and Health, University of Sydney, Sydney, Australia.

Received: 16 December 2020 Accepted: 11 February 2021

Published online: 26 February 2021

\section{References}

1. Barzaghi F, Amaya Hernandez LC, Neven B, Ricci S, Kucuk ZY, Bleesing $J$, et al. Long-term follow-up of IPEX syndrome patients after different therapeutic strategies: an international multicenter retrospective study. J Allergy Clin Immunol.2018;141:1036-1049.e5. https://doi.org/10.1016/j. jaci.2017.10.041.

2. Gambineri E, Ciullini Mannurita S, Hagin D, Vignoli M, Anover-Sombke S, DeBoer S, et al. Clinical, immunological, and molecular heterogeneity of 173 patients with the phenotype of immune dysregulation, polyendocrinopathy, enteropathy, X-linked (IPEX) syndrome. Front Immunol. 2018. https://doi.org/10.3389/fimmu.2018.02411.

3. Buckner JH, Ziegler SF. Functional analysis of FOXP3. Ann N Y Acad Sci. 2008:1143:151-69. https://doi.org/10.1196/annals.1443.014.

4. Campbell DJ, Ziegler SF. FOXP3 modifies the phenotypic and functional properties of regulatory T cells. Nat Rev Immunol. 2007;7:305-10. https:// doi.org/10.1038/nri2061.

5. Xavier-da-Silva MM, Moreira-Filho CA, Suzuki E, Patricio F, Coutinho A, Carneiro-Sampaio M. Fetal-onset IPEX: Report of two families and review of literature. Clin Immunol. 2015;156:131-40. https://doi.org/10.1016/j. clim.2014.12.007.

6. Rae W, Gao Y, Bunyan D, Holden S, Gilmour K, Patel S, et al. A novel FOXP3 mutation causing fetal akinesia and recurrent male miscarriages. Clin Immunol. 2015;161:284-5. https://doi.org/10.1016/j.clim.2015.09.006.

7. Vasiljevic A, Poreau B, Bouvier R, Lachaux A, Arnoult C, Fauré J, et al. Immune dysregulation, polyendocrinopathy, enteropathy, X-linked syndrome and recurrent intrauterine fetal death. Lancet. 2015;385:2120. https://doi.org/10.1016/S0140-6736(15)60773-5.

8. Reichert SL, McKay EM, Moldenhauer JS. Identification of a novel nonsense mutation in the FOXP3 gene in a fetus with hydrops-Expanding the phenotype of IPEX syndrome. Am J Med Genet Part A. 2016;170:226-32. https://doi.org/10.1002/ajmg.a.37401.
9. Louie RJ, Tan QKG, Gilner JB, Rogers RC, Younge N, Wechsler SB, et al. Novel pathogenic variants in FOXP3 in fetuses with echogenic bowel and skin desquamation identified by ultrasound. Am J Med Genet Part A. 2017;173:1219-25. https://doi.org/10.1002/ajmg.a.38144

10. Costa-Carvalho BT, de Moraes-Pinto Ml, de Almeida LC, de Seixas Alves MT, Maia RP, de Souza RL, et al. A remarkable depletion of both Naïve CD4+ and CD8+ with high proportion of memory T cells in an IPEX infant with a FOXP3 mutation in the Forkhead domain. Scand J Immunol. 2008;68:85-91. https://doi.org/10.1111/j.1365-3083.2008.02055.x.

11. Shanes E, Propst L, Ouyang DW, Ernst LM. Recurrent Non immune fetal hydrops associated with IPEX syndrome. Pediatr Dev Pathol. 2019;22:46571. https://doi.org/10.1177/1093526619834809

12. Levy-Lahad E, Wildin RS. Neonatal diabetes mellitus, enteropathy, thrombocytopenia, and endocrinopathy: Further evidence for an X-linked lethal syndrome. J Pediatr. 2001;138:577-80. https://doi.org/10.1067/ mpd.2001.111502.

13. Sohan K, Carroll SG, De La Fuente S, Soothill P, Kyle P. Analysis of outcome in hydrops fetalis in relation to gestational age at diagnosis, cause and treatment. Acta Obstet Gynecol Scand. 2001;80:726-30. https://doi.org/1 0.1034/j.1600-0412.2001.080008726.x.

14. Torgerson TR, Ochs HD. Immune dysregulation, polyendocrinopathy, enteropathy, X-linked: Forkhead box protein 3 mutations and lack of regulatory T cells. J Allergy Clin Immunol. 2007;120:744-50. https://doi. org/10.1016/j.jaci.2007.08.044.

15. Harbuz R, Lespinasse J, Boulet S, Francannet C, Creveaux I, Benkhelifa M, et al. Identification of new FOXP3 mutations and prenatal diagnosis of IPEX syndrome. Prenat Diagn. 2010;30:1072-8. https://doi.org/10.1002/ pd.2613.

16. Wildin RS, Ramsdell F, Peake J, Faravelli F, Casanova JL, Buist N, et al. X-linked neonatal diabetes mellitus, enteropathy and endocrinopathy syndrome is the human equivalent of mouse scurfy. Nat Genet. 2001;27:18-20. https://doi.org/10.1038/83707.

17. Passerini L, Sio F, Porteus M, Bacchetta R. Gene/cell therapy approaches for immune dysregulation polyendocrinopathy enteropathy X-linked syndrome. Curr Gene Ther. 2014;14:422-8. https://doi.org/10.2174/15665 23214666141001123828 .

\section{Publisher's Note}

Springer Nature remains neutral with regard to jurisdictional claims in published maps and institutional affiliations.
Ready to submit your research? Choose BMC and benefit from:

- fast, convenient online submission

- thorough peer review by experienced researchers in your field

- rapid publication on acceptance

- support for research data, including large and complex data types

- gold Open Access which fosters wider collaboration and increased citations

- maximum visibility for your research: over $100 \mathrm{M}$ website views per year

At BMC, research is always in progress.

Learn more biomedcentral.com/submissions 